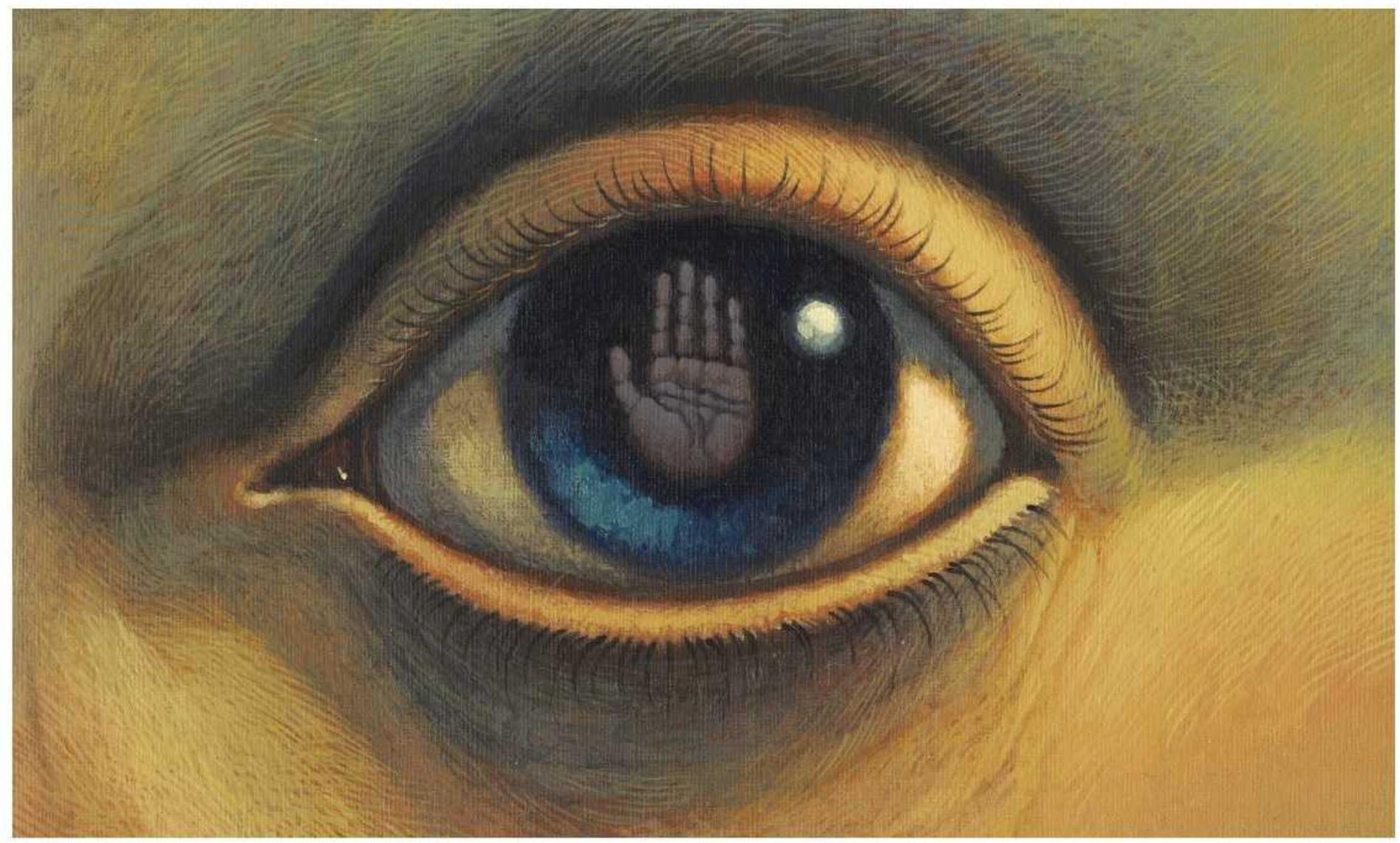

\title{
SCANNING PSYCHOPATHS
}

\section{Are their brains not wired to feel what others feel, or do they just not care? Alison Abbott joins researchers looking into normal neurobiology through the scope of psychopathy.}

$\mathrm{t}$ is a rare event that patient 13 is let out of the high security Dr S. van Mesdag Clinic in Groningen, the Netherlands, and he is making the most of the attention he is getting. Already, the prison guards have had to accompany him from the University of Groningen's functional magnetic resonance imaging (fMRI) scanner to the toilet four times in two hours. The guards indulge him with a shrug. Research psychologist Harma Meffert, who has recruited him for her study, is just as tolerant. That can't be easy, given that she has to spend at least 20 minutes resettling him into the scanner after each interruption

Wearing nothing but blue cotton surgical pyjamas and a constant smile, patient 13 doesn't seem to present much of a threat. In fact with his jewellery removed and his tattoos covered he looks decidedly small and vulnerable. But
"Do they do terrible things to other people because, unlike most of us, they do not share the pain they inflict?" - Christian Keysers and behavioural traits that define the clinical syndrome 'psychopathy'. Lack of empathy is a key feature.

As it happens, Meffert's lab chief, Christian Keysers, the 34-year-old director of the university's neuroimaging centre, is not primarily interested in psychopathy per se. The major focus of his research is empathy - the way we can't help feeling awful when we see a loved one cry, or can't stop our stomach sinking when someone's face darkens in anger. One major theory holds that we understand what another person is feeling by activating the same neural circuitry in our brains that activates when we are experiencing that emotion first hand.

To investigate this trait, Keysers is comparing 'normally' empathic people with those who lack empathy, such as people with autism, and psychopaths. He suspects that psychopaths may be able to no one is forgetting why he was recruited to Meffert's study. Patient 13 has scored the maximum possible on the Psychopathy ChecklistRevised (PCL-R) rating scale, the ubiquitous tool psychiatrists use to identify the personality recognize emotions in others but that they are also able to disconnect that recognition from their own emotions. "Our question is: do they do terrible things to other people because, unlike most of us, they do not share the pain they inflict?" says Keysers. His sophisticated trial design is intended to test whether this is the case (see 'Letting fingers do the talking').

Although not all diagnosable psychopaths are criminally inclined or in prison, places such as the Groningen clinic serve as a concentrated source. And they provide screening. The PCL-R scale is practically the only tool available for this purpose. In PCL-R assessment, specially trained psychiatrists discuss hundreds of issues with the patient during semi-structured interviews. On the basis of these interviews, and information about past behaviour from independent sources, such as social workers' reports, they build up a four-part assessment. The headings are: 'interpersonal', covering behaviour such as manipulativeness and lying; 'affective', covering irresponsibility and lack of empathy and remorse; 'lifestyle', tracking impulsivity and need for stimulation; and 'antisocial', which looks for records of things such as juvenile delinquency. Those on the receiving end of the assessment find it tiresome.

It is, of course, not easy to put together a group of imprisoned psychopaths for an academic research project, but the Dutch Ministry of Justice provides generous access. "We have a legal duty to try to treat all those criminals who 
are found guilty but not responsible for their actions due to insanity," says Jacqueline Hochstenbach, a department head at the ministry.

Although the Groningen project doesn't aim to treat or cure psychopathy, there's a general sense even among the subjects that such basic research could at least help illuminate what is wrong. For psychopaths who are deemed dangerous, there are no therapeutic options. "We know there is no effective treatment for psychopathy," says Hochstenbach. Pharmaceuticals don't help and those who receive behavioural therapy have a higher - not lower - rate of recidivism.

In 2004, like other countries, the Netherlands institutionalized PCL-R testing in forensic psychiatric centres, where it is used as a risk-assessment tool for patients being considered for parole. Developed over the past three decades by psychologist Robert Hare from the University of British Colombia in Vancouver, Canada ${ }^{1}$, it has proved to be a powerful predictor of the likelihood that a criminal will reoffend.

\section{A qualifying score}

To qualify for the empathy study, participants must score higher than 30 on the PCL-R scale, out of a maximum possible score of 40 . Qualifiers are told they will participate, but not when - to give no opportunity to plan escape. On the morning of the test, they are asked to confirm their consent and Meffert goes through the protocol again in more detail. She does not, however, explain the detailed scientific aims of the study in case the subjects try to manipulate the outcome.

Inside the clinic, Meffert is often alone with her subjects but wears an alarm around her neck. "Once I pressed it by accident and was amazed to find myself surrounded by several guards who seemed to spring from nowhere within seconds," she says. "I feel safe." Meffert is a calm person,

\section{"Some psychopathic} features are not necessarily a bad thing for society - in some professions they may even help."

\section{- Robert Hare}

An hour later he is on the road, in an armoured van. No metal is allowed near the scanner. Even his tattoos nearly ruled him out as a subject, but they are small, and also recent enough that the red in them is likely to be from newer, iron-free 3's trouser leg, preventing him from runa special non-metal material.

Patient 13 doesn't seem to think much of the experiment itself. The sequence of film clips, which are projected inside the scanner directly above his face, only run for ten minutes or so. But he finds it hard to concentrate and his eyelids, observed remotely by the researchers in the adjacent control room, begin to droop. Meffert runs the clip again - the experiwho works well with her subjects by talking and listening to them seriously. But she says that psychopathic people can be very tiring to work with because they command, and need, intense attention.

On the morning of his test-day interview, patient 13 , although taken by surprise, is looking what must be close to his best. His hair and beard are fashionably trimmed, and his clothes are casual but coordinated. Walking to the small interview room, he says he wishes he had more notice, but he is laughing. He listens to Meffert's detailed explanation of how the day will run and gives his agreement. ment requires the subject's full attention.

Most of the others who have taken part in easier to handle in the scanner than patient 13 - often they are more cooperative than the average student volunteer, says Meffert. All the subjects seemed to find the experiment inmate Willem Boerema (not his real name), who claims to have taken part only because he likes Meffert. Then, contradicting himself, he adds that "if they say the study can help people then it's good".

Boerema, smart, articulate and multilingual, the study were much more compliant and to be nonsense. "It was stupid, boring," says has a PCL-R rating of 35 - and a big problem with the term 'psychopath'. He views it as a fashionable label abused by the judicial system to keep people like himself from being released. "The courts look at your PCL-R rating and add two years to your sentence, then another two years, and then another."

\section{Damaging label}

When he entered the prison five years ago, Boerema says, 'borderline personality' was the fashionable term, and his designated pigeonhole. "The psychopathy label is more damaging though - it prompts everyone to see you as a potential serial killer, which I could never be." (Note, in reporting this article it was agreed that inmates' crimes would be neither asked about nor reported on.) But Boerema also wears the score as a badge of honour: "I think my high psychopath score is a talent, not a sickness - I can make good strong decisions, and it's good to have some distance with people."

There is some truth in this, says Hare. As well as developing the PCL-R, he has also developed a shorter version suitable for screening the general population (PCL-SV, with the SV standing for screening version). He has used it to estimate that maybe $1 \%$ are psychopathic, even if they have never committed a crime, according to research presented recently at a meeting on psychopathy research. "Some psychopathic features are not necessarily a bad thing for society - in some professions they may even help," says Hare. "Too much empathy, for example, on the part of a police officer or a politician would interfere with the job." 
In theory, scientists like Keysers could recruit high-scoring psychopaths from the general population as control subjects for studies on empathy. But identifying enough of them would be extremely time consuming. Some scientists without access to the captive population in prisons - a fifth of whom may be psychopathic according to $\mathrm{Hare}^{2}$ - have turned to populations on the outside with specific behavioural problems.

Neuroscientist Jorge Moll, for example, from the LabsD’Or Hospitals network in Rio de Janeiro, Brazil, screened and recruited 'troublesome' outpatients of a civil psychiatric centre for his ongoing neuroimaging study to identify the neural circuits involved in moral judgement. Drug use, which can interfere with results, is a bigger hazard in those outside prisons than those inside, he concedes, "but the standards of security in Brazil don't make a prison study feasible here".

James Blair at the National Institutes of Health in Bethesda, Maryland, gets around the drug problems who score highly on the PCL-SV rating, and whose parents have responded to his advertisement. Kent Kiehl, now at the University of New Mexico in Albuquerque, has worked with parole populations in Connecticut, but found the subjects so unreliable that he spent three-quarters of his time getting them to keep appointments. New Mexico is one of several US states that, like the Netherlands, are keen to promote psychopathe most of the supportive environment and developed a mobile fMRI machine to conduct a dozen or so different studies - from empathy and moral reasoning to cognitive function on 300 inmates. "Going into the prison means you can get many more subjects than would be possible by bringing them out individually with all the arrangements that requires," he says. "Larger subject num-

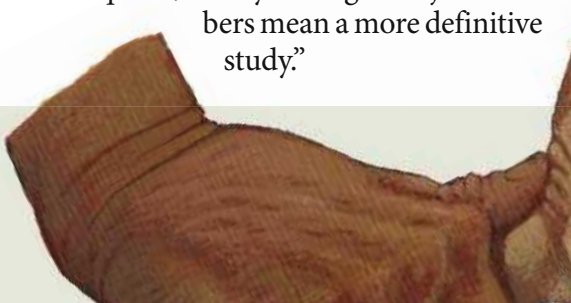

problem by using children with behavioural thy research. Kiehl has made

All of these psychopathy researchers believe that their work will lead to a level of understanding of the condition that could eventually lead to a treatment. Keysers does too - even though his prime motivation in recruiting psychopaths was to support his empathy research. He now finds himself "fascinated by the phenomenon of the untreatable psychopath", and also convinced that there will one day be a fix. Patient 13, meanwhile, has finished his test day wearing the same smile he set out with. If a form of therapy were ever to emerge, it is not clear whether people like him - who do not consider themselves sick - would be willing to take it.

\section{Alison Abbott is Nature's Senior European}

\section{Correspondent.}

\section{Letting fingers do the talking}

'Normal' people run simulations in their brain mirroring what others feel. This means that when they see someone expressing (through facial expressions and gestures) a particular emotion, some of the same circuitry is activated in their own brains that would be activated if they were feeling that emotion themselves ${ }^{3}$. This circuitry feeds into cognitive and emotional processes. So the empathy is both an intellectual and an emotional process.

Psychopaths have a number of defining features, one being a pronounced lack of empathy. Do these individuals fail to mirror the emotions of others, or do they detach the emotional component when the mirroring process happens? Christian Keysers, the director of the Neuroimaging Centre at the University of Groningen in the Netherlands has designed an experiment to address this question.

Most researchers studying empathy or specific emotions have their subjects look at a series of faces wearing different expressions. An angry or fearful face, for example, typically activates a brain area called the amygdala among other areas in the relevant neurocircuit. This activation can be seen indirectly using functional magentic resonance imaging, which measures changes in the brain's regional blood oxygenation.

Keysers saw limitations to this paradigm for his own research. "With faces you are optimizing the brain responses for particular areas - and those areas are going to be the only ones where you'll be able to see any potential difference between psychopaths and non-psychopaths of the same age and educational background," he says. He wanted to develop a paradigm where there would be activation in many brain areas, so that differences in activation could be seen in circuits without preconceived theories about which
1. Hare, R. D. in The International Handbook of Psychopathic Disorders and the Law (eds Felthous, A. \& Sass, H.) 41-67 (John Wiley, Chichester, UK, 2007).

2. Hare, R. D. Manual for the Revised Psychopathy Checklist 2nd edn (Multi-Health Systems, Toronto, Ontario, Canada, 2003).

3. Keysers, C. \& Gazzola, V. Prog. Brain Res. 156, 379-401 (2006).

subject has to watch the movies again, but this time must put himself in the shoes of either the victim or the perpetrator. Then, once outside the scanner, the subject is asked to rate how positively or negatively he perceived the gestures on a scale of one to five.

Finally - to identify brain circuits involved when the subject is directly exposed to emotionally laden hand gestures, rather than just watching them - the experimenter repeats the same hand interactions on the hands of the subject - stroking, twisting, shaking, slapping away each of their hands in turn while inside the scanner. The subject again responds using the sliding scale.

"The paradigm with the interacting hands activates many parts of the brain, including those involved in processing movement, touch and emotion - so we hope we'll be able to identify areas that are activated by the normally empathic, but not activated by those who lack empathy," says Keysers.

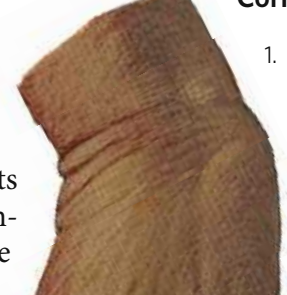

